\title{
P-glycoprotein-mediated chemoresistance is reversed by carbonic anhydrase XII inhibitors
}

\author{
Joanna Kopecka ${ }^{1}$, Gregory M. Rankin ${ }^{2}$, Iris C. Salaroglio ${ }^{1}$, Sally-Ann Poulsen ${ }^{2, *}$, \\ Chiara Riganti ${ }^{1, *}$ \\ ${ }^{1}$ Department of Oncology, University of Torino, 10126 Torino, Italy \\ ${ }^{2}$ Eskitis Institute for Drug Discovery, Griffith University, Brisbane, Nathan, Queensland, 4111, Australia \\ *These authors contributed equally to this work
}

Correspondence to: Sally-Ann Poulsen, email: s.poulsen@griffith.edu.au Chiara Riganti, email: chiara.riganti@unito.it

Keywords: carbonic anhydrase XII, P-glycoprotein, doxorubicin, chemoresistance, intracellular pH

Received: August 26, 2016

Accepted: October 28, 2016

Published: November 03, 2016

\section{ABSTRACT}

Carbonic anhydrase XII (CAXII) is a membrane enzyme that maintains pH homeostasis and sustains optimum P-glycoprotein (Pgp) efflux activity in cancer cells. Here, we investigated a panel of eight CAXII inhibitors (compounds 1-8), for their potential to reverse Pgp mediated tumor cell chemoresistance. Inhibitors ( $5 \mathrm{nM}$ ) were screened in human and murine cancer cells (colon, lung, breast, bone) with different expression levels of CAXII and Pgp. We identified three CAXII inhibitors (compounds 1, 2 and 4 ) that significantly ( $\geq 2$ fold) increased the intracellular retention of the Pgp-substrate and chemotherapeutic doxorubicin, and restored its cytotoxic activity. The inhibitors lowered intracellular pH to indirectly impair Pgp activity. Ca12-knockout assays confirmed that the chemosensitizing property of the compounds was dependent on active CAXII. Furthermore, in a preclinical model of drug-resistant breast tumors compound $1(1900 \mathrm{ng} / \mathrm{kg})$ restored the efficacy of doxorubicin to the same extent as the direct Pgp inhibitor tariquidar. The expression of carbonic anhydrase IX had no effect on the intracellular doxorubicin accumulation. Our work provides strong evidence that CAXII inhibitors are effective chemosensitizer agents in CAXII-positive and Pgp-positive cancer cells. The use of CAXII inhibitors may represent a turning point in combinatorial chemotherapeutic schemes to treat multidrug-resistant tumors.

\section{INTRODUCTION}

Carbonic anhydrases (CA, EC 4.2.1.1) are highly conserved and ubiquitous zinc metalloenzymes that reversibly hydrate carbon dioxide to bicarbonate and a proton: $\mathrm{CO}_{2}+\mathrm{H}_{2} \mathrm{O} \leftrightarrows \mathrm{HCO}_{3}^{-}+\mathrm{H}^{+}$, controlling intracellular $\mathrm{pH}\left(\mathrm{pH}_{\mathrm{i}}\right)$ [1]. CAIX and CAXII, two integral membrane proteins with the catalytic domain on the extracellular side, are overexpressed in many solid and hypoxic tumors [2-5]. Given the expression prevalence of CAXII in transformed cells, high levels of tissue-associated and circulating CAXII have been proposed as predictive markers of thyroid [6] and squamous lung [7] cancers, respectively. CAXII overexpression has also been associated with poor prognosis in human gliomas [8], oral squamous cancer [9] and esophageal squamous cell cancer [10]. In cancer cells CAXII contributes to extracellular acidification while also maintaining a normal intracellular $\mathrm{pH}\left(\mathrm{pH}_{\mathrm{i}}\right)$. CAXII hydrates tumor cell generating $\mathrm{CO}_{2}$. As a consequence $\mathrm{H}^{+}$ ions are trapped extracellularly, lowering $\mathrm{pH}$ outside the cell $\left(\mathrm{pH}_{\mathrm{o}}\right.$ ), while $\mathrm{HCO}_{3}^{-}$is taken up by the cell to buffer the intracellular $\mathrm{pH}\left(\mathrm{pH}_{\mathrm{i}}\right)$. $[11,12]$. In healthy tissues CAXII is expressed mainly in the kidney and large intestine, with minimal expression in other tissues. The acid-base equilibrium regulated by CAXII is associated with $\mathrm{Na}^{+}$and $\mathrm{Cl}^{-}$transport that in turn drives passive water absorption in these organs $[2,13]$.

The inhibition of CAXII has been associated with impaired tumor growth, with a CAXII-inhibitory monoclonal antibody showing significant antitumor properties in mouse xenografts of breast cancer [14]. There is no corresponding study to correlate effects of 
small molecule CAXII inhibition with CAXII expression in tumors, however CAXII inhibitors have demonstrated antimetastatic activity in a breast cancer xenograft [15].

We recently demonstrated that CAXII is overexpressed in chemoresistant cancer cells expressing the drug efflux transporter P-glycoprotein (Pgp) [16]. Pgp recognizes multiple substrates, including a broad range of chemotherapeutics. Pgp expression in cancer cells contributes to multidrug resistance (MDR) $[17,18]$. CAXII physically interacts with Pgp and it has been proposed that CAXII maintains the optimal $\mathrm{pH}$ for Pgp efflux activity, thus potentiating the contribution of Pgp to MDR [13].

Given the correlation of CAXII activity with tumor proliferation, invasion and chemoresistance, the interest in developing selective inhibitors of CAXII has increased in recent years, however in vitro and in vivo studies with small molecule CAXII inhibitors that directly link the mechanism of action to CAXII inhibition remain scarce and CAXII is much less studied than the other cancerassociated CA, CAIX.

The aim of this study is to evaluate CAXII inhibitors as selective chemosensitizers in MDR tumor models. Eight test inhibitors with variable CA inhibition profiles and variable physicochemical properties were selected to establish the potential of CAXII inhibitors to indirectly inhibit Pgp activity to resensitize MDR cells to doxorubicin. We show that CAXII inhibitors have very good chemosensitizing efficacy, and increase the effectiveness of the chemotherapeutic drug doxorubicin up to 4.4-fold. This correlated with high expression of both CAXII and Pgp in vitro and in vivo. Our results demonstrate that small molecule CAXII inhibitors may have future applications in clinical settings, for example, by allowing a reduction in the dosage of cytotoxic drugs or To restore the cytotoxic efficacy of existing drugs that have lost their effectiveness i.e. resensitizing of hard-totreat tumors to chemotherapeutics.

\section{RESULTS}

\section{Selective CAXII inhibitors increase doxorubicin accumulation and cytotoxicity in CAXII-positive and Pgp-positive cancer cells}

The CA inhibition, CAXII selectivity and cLog $P$ values for inhibitors 1-8 (Figure 1) are given in Table 1 .

On the basis of the $K_{\mathrm{i}}$ values for 1, 2 and 4-8 at CAXII $\left(K_{\mathrm{i}}<10 \mathrm{nM}\right)$, all the compounds were evaluated at $5 \mathrm{nM}$ concentrations in the following in vitro assays. In these experimental conditions, compounds 1, 2 and 4 increased the intracellular accumulation of doxorubicin, a Pgp substrate, in cells with high expression of both CAXII and Pgp (Supplementary Figure S1), such as HT29/DX, A549/DX, MDA-MB-231, TUBO, JC, U2OS/ DX and SaOS/DX cells (Figure 2A-2J). The compounds had no effect on cells with detectable levels of just one of these two proteins expressed (Supplementary Figure S1), such as HT29, A549, MCF7, SKBR3, T74D, U2OS and $\mathrm{SaOS}$ cells (Figure 2A-2J). The expression of CAIX did not influence the effects of the compounds on the intracellular doxorubicin accumulation in all cell lines tested. Compound 3 (CAXII $K_{\mathrm{i}}=96 \mathrm{nM}$ ) has low activity as a CAXII inhibitor, however was included in the study as it is a prodrug of compound 2, an active CAXII inhibitor (CAXII $K_{\mathrm{i}}=7.3 \mathrm{nM}$ ). Consequently compounds 2 and 3 provide a 'drug/prodrug' pair where the observed activity of the 'drug' may be predominantly attributed to 2. Compounds 1, 2 and 4 were the most consistently effective at increasing the intracellular accumulation of doxorubicin across all CAXII-positive and Pgp-positive cell lines tested, showing the same potency as the direct Pgp inhibitor, tariquidar (Figure 2A-2J). The compounds also increased the intracellular retention of the chemotherapeutics vinblastine (Supplementary Figure S2A) and paclitaxel (Supplementary Figure S2B), two Pgp substrates with different Pgp binding sites [19]. Compounds 1, 2 and 4 were selected for the follow-up assays, described next.

In accordance with the correlation of CAXII expression and cancer cell proliferation [14], compounds 1,2 and 4 reduced the viability of CAXII-positive cell lines. The reduction in viability for individual compounds was: $\leq 31 \pm 6 \%$ in HT29/DX cells, $\leq 28 \pm 10 \%$ in A549 cells, $\leq 38 \pm 7 \%$ in A549/DX cells, $\leq 33 \pm 12 \%$ in T74D cells, $\leq 36 \pm 11 \%$ in MDA-MB-231 cells, $\leq 28 \pm 7 \%$ in TUBO cells, $\leq 30 \pm 10 \%$ in JC cells, $\leq 27 \pm 8 \%$ in U2OS/ DX cells, $\leq 32 \pm 7 \%$ in SaOS/DX cells $(p<0.05$ for all cell lines; $n=4)$. In contrast, the compounds were devoid of any effects on viability in cells with low or undetectable levels of CAXII, including HT29, MCF7, SKBR3, U2OS, $\mathrm{SaOS}$ cell lines (not shown). As expected, doxorubicin reduced viability in cells with undetectable or low levels of Pgp, i.e. HT29, A549, MCF7, SKBR3, T74D, U2OS and $\mathrm{SaOS}$ cells; in these doxorubicin-sensitive cell lines the compounds did not exert additive effects on viability compared to doxorubicin treatment alone (not shown). In contrast, HT29/DX, A549/DX, MDA-MB-231, TUBO, JC, U2OS/DX, SaOS/DX cells, which are positive for both Pgp and CAXII (Supplementary Figure S1), were unresponsive to doxorubicin alone not shown. Compounds 1, 2 and 4 restored doxorubicin efficacy and further reduced cell viability. The differences in cell viability between cells treated with compounds alone and cells co-treated with compounds plus doxorubicin were: $\geq 38 \pm 6 \%$ in HT29/DX cells, $\geq 22 \pm 8 \%$ in A549 cells, $\geq 38 \pm 7 \%$ in A549/DX cells, $\geq 18 \pm 7 \%$ in T74D cells, $\geq 34 \pm 10 \%$ in MDA-MB-231 cells, $\geq 22 \pm 8 \%$ in TUBO cells, $\geq 29 \pm 8 \%$ in JC cells, $\geq 27 \pm 9 \%$ in U2OS/DX cells, $\geq 27 \pm 7 \%$ in SaOS/DX cells, $(p<0.05 ; n=4)$. These differences suggest that the decreased viability of cells co-treated with CAXII inhibitors and doxorubicin was due to the increased doxorubicin accumulation with added compound 1, 2 or 4 and/or to a synergistic effect of compound 1,2 or 4 and doxorubicin, rather than to 
Table 1: Inhibition data $\left(K_{i}\right)$ of human CA isozymes I, II, IX and XII, CAXII selectivity and cLog $P$ values of compounds 1-8 and the established CA inhibitor acetazolamide (AZA)

\begin{tabular}{lcccccccc}
\hline \multirow{2}{*}{ Compd } & \multirow{2}{*}{$\mathbf{c L o g}^{\mathbf{a}}$} & \multicolumn{4}{c}{$\boldsymbol{K}_{i}(\mathbf{n M})^{\mathbf{b}}$} & \multicolumn{3}{c}{ CAXII Isozyme Selectivity $^{\mathbf{c}}$} \\
\cline { 2 - 8 } & & $\mathbf{C A}$ I & CA II & CA IX & CA XII & CA I/XII & CAII/ XII & CA IX/XII $^{\text {CA }}$ \\
\hline $\mathbf{1}$ & -2.65 & 9000 & 5.0 & 2.0 & 1.0 & 9000 & 5.0 & 2.0 \\
$\mathbf{2}$ & -3.30 & 1180 & 82 & 8.6 & 7.3 & 161 & 11.2 & 1.2 \\
$\mathbf{3}$ & +1.40 & 3360 & 105 & 77 & 96 & 35 & 1.1 & 0.8 \\
$\mathbf{4}$ & -3.30 & 4500 & 93 & 62 & 7.6 & 592 & 12.2 & 8.2 \\
$\mathbf{5}$ & -3.17 & 102 & 9.1 & 95 & 8.3 & 12.3 & 1.1 & 11.5 \\
$\mathbf{6}$ & -3.17 & 87 & 7.8 & 99 & 8.7 & 10 & 0.9 & 11.4 \\
$\mathbf{7}$ & -4.94 & 107 & 5.0 & 106 & 8.9 & 12.0 & 0.6 & 11.9 \\
$\mathbf{8}$ & -4.94 & 101 & 4.8 & 98 & 8.2 & 12.3 & 0.6 & 12.0 \\
AZA & -1.00 & 250 & 12 & 25 & 5.7 & 43.9 & 2.1 & 4.4 \\
\hline
\end{tabular}

${ }^{a}$ Calculated using ChemDraw Ultra 12 or InstantJChem 3.0.4 from ChemAxon. ${ }^{b}$ Errors in the range of $\pm 5 \%$ of the reported value, from three determinations. ${ }^{c}$ Selectivity is determined by the ratio of $K_{\mathrm{i}} \mathrm{s}$ for CA isozyme relative to CAXII. Nonstandard abbreviations: cLog P (calculated Log P partician coefficient of the compound between octanol and water), $K_{\mathrm{i}}$ (inhibition constant).

cytotoxicity exerted by the CAXII inhibitors themselves. Accordingly, the doxorubicin $\mathrm{IC}_{50}$ was significantly reduced by the co-treatment with the CAXII inhibitors in these cell lines. Co-treatment with compounds 1, 2 and 4 had the same efficacy as treatment with tariquidar (Figure $3 \mathrm{~A}-3 \mathrm{~J}$ ) in resensitizing cells to doxorubicin (Table 2). Notably, in CAXII-negative MCF7 and SKBR3 cells that overexpress Pgp (Supplementary Figure S3A), the compounds did not increase the intracellular retention of doxorubicin (Supplementary Figure S3B). Lastly, compounds 1, 2 and 4 did not exert any cytotoxic effect (Supplementary Figure S4B) in not-transformed human epithelial colon CCD-Co-18 cells, epithelial lung BEAS-2B cells, epithelial breast MCF10A cells or fibroblasts that do not have detectable levels of CAXII (Supplementary Figure S4A). Collectively these results demonstrate that compounds 1,2 and 4 are cytotoxic agents against CAXII-positive cancer cells and substantially reverse doxorubicin resistance in cancer cells expressing both CAXII and Pgp, but are without significant cytotoxicity in CAXII-negative and nottransformed cells.

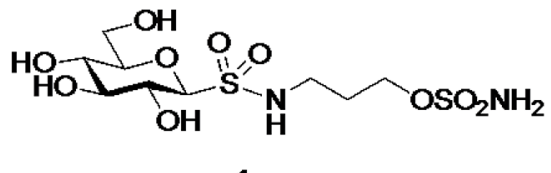

1

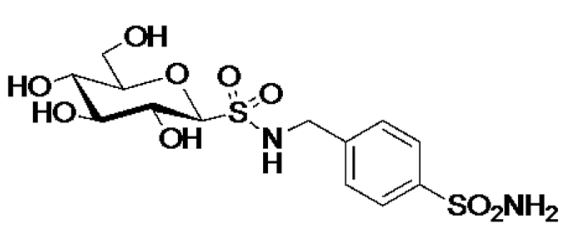

5

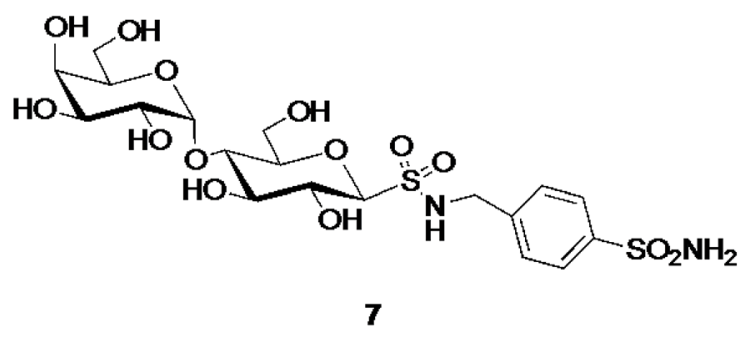

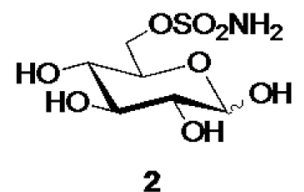
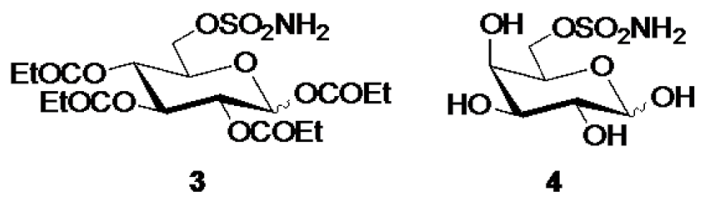

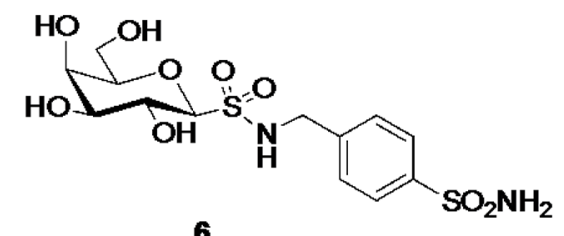

6

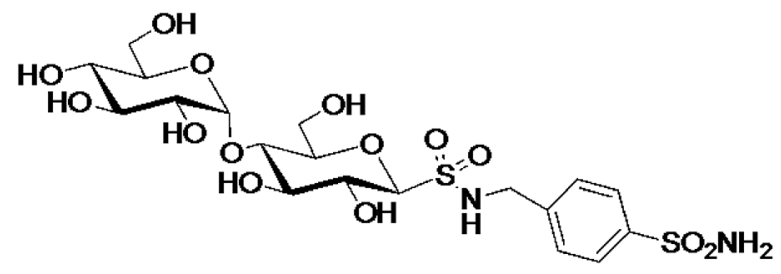

8

Figure 1: Chemical structure of CAXII inhibitors. 

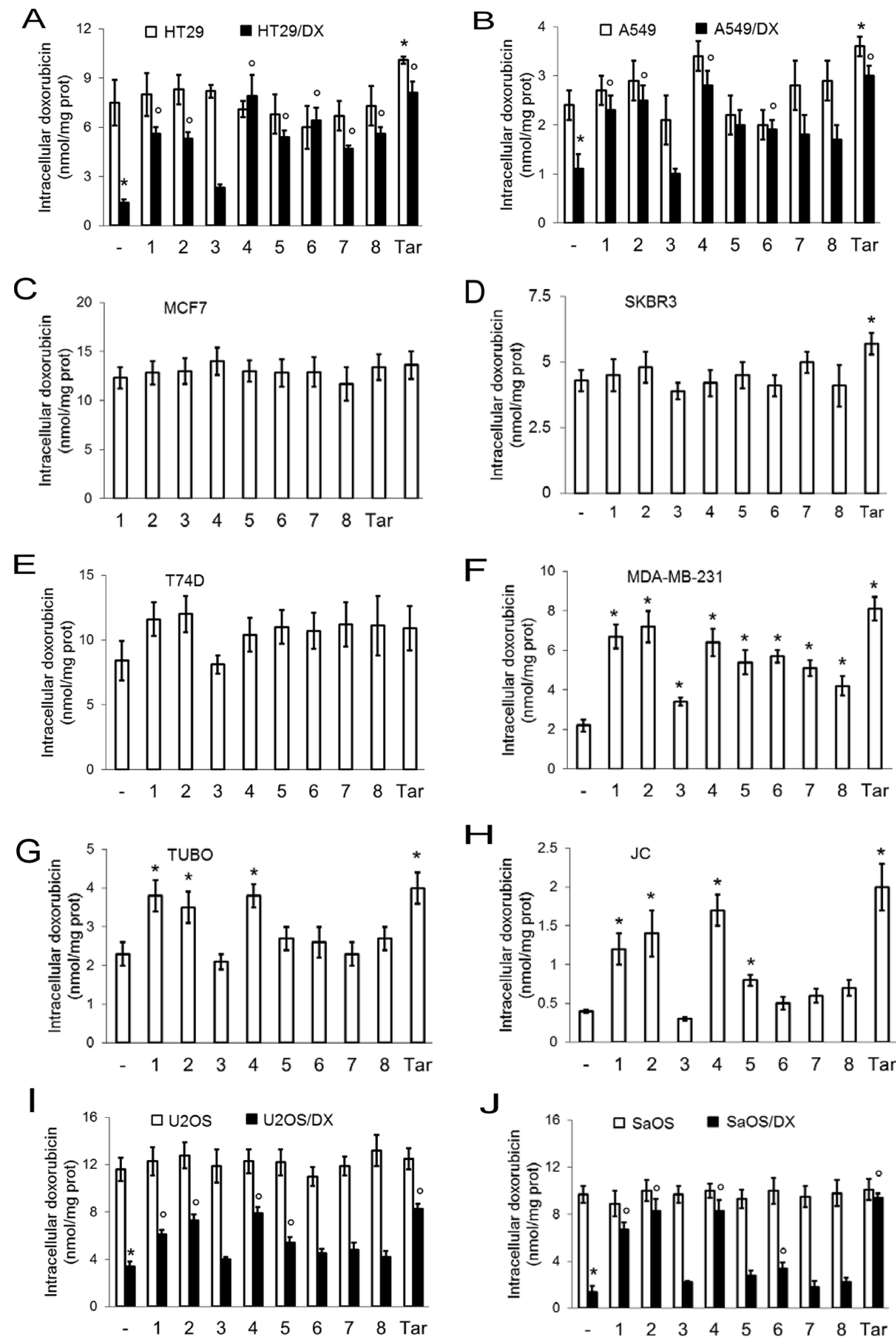

Figure 2: Effects of CAXII inhibitors on intracellular doxorubicin retention in drug-sensitive and drug-resistant cancer cells. Human doxorubicin-sensitive colon cancer HT29 cells and their resistant counterpart HT29/DX cells (panel A), human doxorubicinsensitive lung cancer A549 cells and their resistant counterpart A549/DX cells (panel B), human doxorubicin-sensitive and resistant breast cancer MCF7 (panel C), SKBR3 (panel D), T74D (panel E) and MDA-MB-231 cells (panel F), murine doxorubicin-resistant TUBO (panel G) and JC cells (panel $\mathbf{H}$ ), human doxorubicin-sensitive osteosarcoma U2OS cells and their resistant counterpart U2OS/DX cells (panel I), human doxorubicin-sensitive osteosarcoma Saos and their resistant counterpart SaOS/DX (panel J) were grown for $24 \mathrm{~h}$ in the presence of $5 \mu \mathrm{M}$ doxorubicin, alone (-) or in the presence of $5 \mathrm{nM}$ of compounds 1-8. Tariquidar (25 nM; Tar) was included as Pgp inhibitor. The intracellular drug content was measured fluorimetrically. Data are presented as means $\pm \operatorname{SD}(n=4)$. Versus doxorubicin alone $(-):{ }^{*} p<0.05$; for cells treated with compounds $1-8$ or tariquidar, doxorubicin-resistant cells versus the corresponding doxorubicin-sensitive cells: ${ }^{0} p<0.05$. 

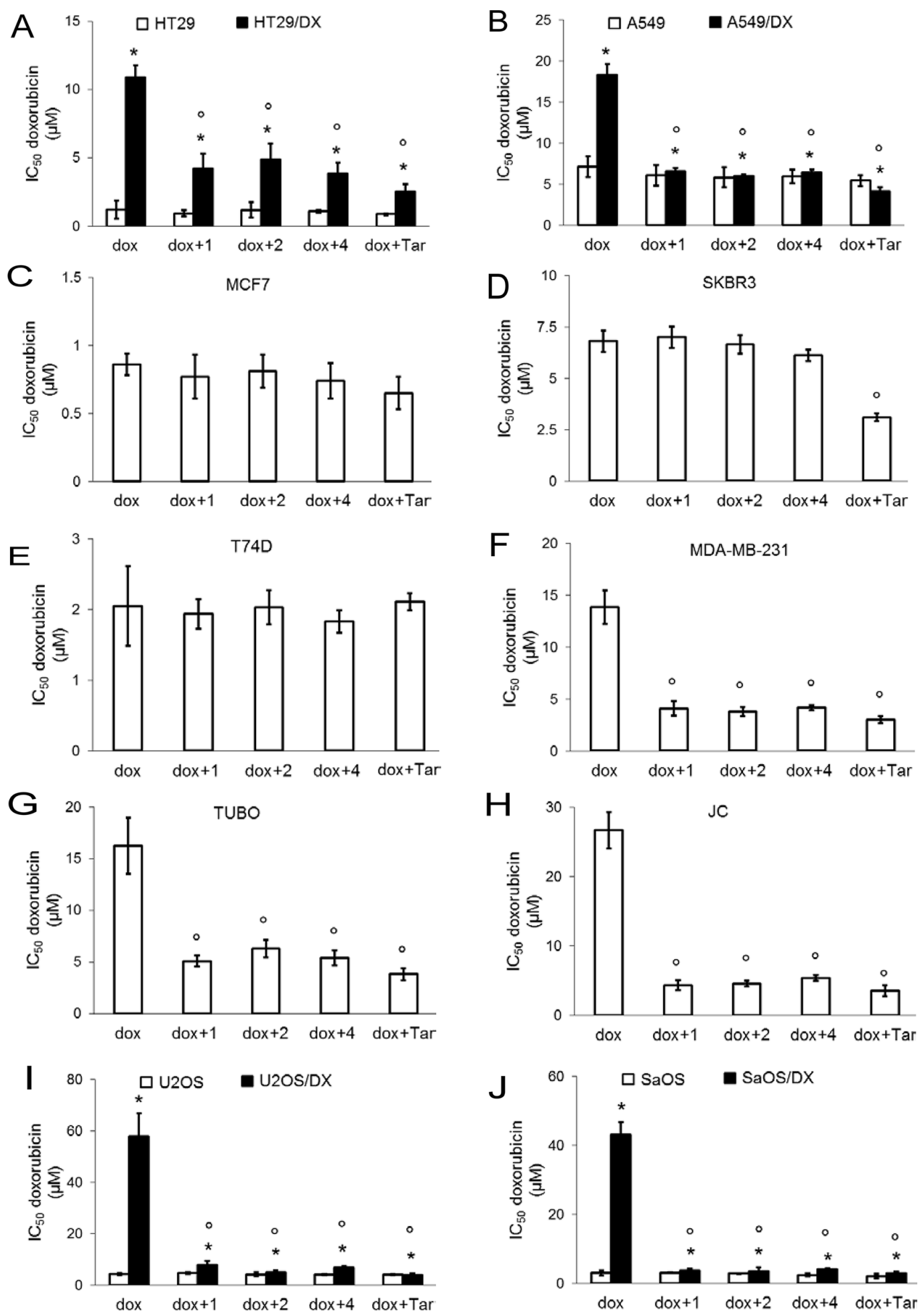

Figure 3: Effects of CAXII inhibitors on viability of drug-sensitive and drug-resistant cancer cells. Human doxorubicinsensitive colon cancer HT29 cells and their resistant counterpart HT29/DX cells (panel A), human doxorubicin-sensitive lung cancer A549 cells and their resistant counterpart A549/DX cells (panel B), human doxorubicin-sensitive and resistant breast cancer MCF7 (panel C), SKBR3 (panel D), T74D (panel E) and MDA-MB-231 cells (panel F), murine doxorubicin-resistant TUBO (panel G) and JC cells (panel H), human doxorubicin-sensitive osteosarcoma U2OS cells and their resistant counterpart U2OS/DX cells (panel I), human doxorubicinsensitive osteosarcoma Saos and their resistant counterpart SaOS/DX (panel J) were incubated for $72 \mathrm{~h}$ with increasing concentrations $(1 \mathrm{nM}-1 \mathrm{mM})$ of doxorubicin (dox), alone or in the presence of $5 \mathrm{nM}$ of compound 1, 2 and 4, then stained in quadruplicate with neutral red. Tariquidar ( $25 \mathrm{nM}$; Tar) was included as a Pgp inhibitor. $\mathrm{IC}_{50}$ of tariquidar alone was $>10 \mu \mathrm{M}$; at $25 \mathrm{nM}$ tariquidar reduced viability $\leq 8.23 \pm 1.44 \%$ in each cell line. Data are presented as mean $\mathrm{IC}_{50} \pm \mathrm{SD}(n=4)$. HT29/DX, A549/DX, U2OS/DX, SaOS/DX versus HT29, A549, U2OS, SaOS cells: * $p<0.001$; versus doxorubicin alone: ${ }^{\circ} p<0.005$. 
Table 2: Resistance factor ( $\mathrm{Rf})$ of cell lines treated with doxorubicin alone or doxorubicin in the presence of compounds 1,2 and 4, versus cells treated with doxorubicin plus tariquidar

\begin{tabular}{lcccc}
\hline Cell line & Rf dox & Rf dox $\mathbf{1}$ & Rf dox + 2 & Rf dox +4 \\
\hline HT29 & 1.39 & 1.07 & 1.35 & 1.23 \\
HT29/DX & 4.26 & 1.66 & 1.91 & 1.52 \\
A549 & 1.31 & 1.21 & 1.08 & 1.09 \\
A549/DX & 4.45 & 1.59 & 1.46 & 1.57 \\
MCF7 & 1.32 & 1.18 & 1.25 & 1.14 \\
SKBR3 & 2.19 & 2.25 & 2.14 & 1.97 \\
T74D & 0.98 & 0.92 & 0.96 & 0.88 \\
MDA-MB-231 & 4.55 & 1.34 & 1.25 & 1.37 \\
TUBO & 4.23 & 1.33 & 1.64 & 1.41 \\
JC & 7.61 & 1.23 & 1.29 & 1.54 \\
U2OS & 1.05 & 1.14 & 1.02 & 0.99 \\
U2OS/DX & 15.44 & 2.02 & 1.31 & 1.76 \\
SaOS & 1.43 & 1.47 & 1.36 & 1.18 \\
SaOS/DX & 14.97 & 1.32 & 1.26 & 1.42 \\
\hline
\end{tabular}

Cells were incubated for $72 \mathrm{~h}$ with increasing concentrations ( $1 \mathrm{nM}-1 \mathrm{mM})$ of doxorubicin (dox), alone or in the presence of $5 \mathrm{nM}$ of compound 1, 2 and 4, then stained in quadruplicate with neutral red. Tariquidar ( $25 \mathrm{nM}$, for $24 \mathrm{~h}$; Tar) was included as Pgp inhibitor $(n=4)$. $\mathrm{Rf}$ (resistance factor) was calculated as the ratio between mean $\mathrm{IC}_{50}$ in cells treated with compound 1,2 and 4 , and mean $\mathrm{IC}_{50}$ in cells treated with doxorubicin and tarquidar.

\section{Selective CAXII inhibitors lower Pgp ATPase activity and alter intracellular pH}

CAXII and Pgp proteins co-immunoprecipitated (Figure 4A) in HT29/DX, A549/DX, MDA-MB-231, TUBO, JC, U2OS/DX and SaOS/DX cells, which express both CAXII and Pgp (Supplementary Figure S1), as well as in Pgp-enriched vesicles derived from the membranes of these cells (Supplementary Figure S5), indicating that these two enzymes were physically associated in the cell plasma membrane. Treatment of these doxorubicin-resistant cell lines with CAXII inhibitors 1,2 and $4(5 \mathrm{nM})$ lowered the $\mathrm{pH}_{\mathrm{i}}$ relative to untreated cells: compound 1 (CAXII $K_{\mathrm{i}}=$ $1.0 \mathrm{nM})$ reduced $\mathrm{pH}_{\mathrm{i}} \geq 0.24$ units, compound $2(\mathrm{CAXII}=$ $K_{\mathrm{i}} 7.3 \mathrm{nM}$ ) reduced $\mathrm{pH}_{\mathrm{i}} \geq 0.12$ units, compound 4 (CAXII $=K_{\mathrm{i}} 7.6 \mathrm{nM}$ ) reduced $\mathrm{pH}_{\mathrm{i}} \geq 0.06$ units (Supplementary Figure S6). Isolated Pgp has consistent basal activity across the $\mathrm{pH}$ range 6.2 to $7.6\left(\right.$ at $37^{\circ} \mathrm{C}$ ) [16], this range encompasses the $\mathrm{pH}_{\mathrm{i}}$ of the resistant cancer cell lines tested (Supplementary Figure S6). Notably, the reduction of $\mathrm{pH}_{\mathrm{i}}$ exerted by compounds 1, 2 and 4 (Supplementary Figure S6) was paralleled by a modest, but significant reduction ( $\geq 1.47$-fold) of Pgp ATPase activity (Figure 4B). The compounds also reduced the substrate-dependent activation of Pgp, as demonstrated by the ATPase assays performed in the presence of Pgp substrate doxorubicin (Supplementary Figure S7). In contrast, in the presence of the Pgp inhibitor tariquidar, which strongly decreased ATPase activity, there was no further reduction of ATPase activity by co-treatment of tariquidar with compounds 1,2 and 4 (Supplementary Figure S7).

\section{Knockout of ca12 abrogates the effects of CAXII inhibitors on doxorubicin accumulation and cytotoxicity}

To confirm that the chemosensitizing effect of compounds 1, 2 and 4 was dependent on CAXII activity, we knocked-out cal2 in a selection of the CAXII-positive and Pgp-positive cell lines: HT29/DX, A549/DX, MDAMB-231 and U2OS/DX cells (Figure 5A). Compounds 1, 2 and 4 lost the ability to further increase the doxorubicin intracellular accumulation (Figure 5B) in cal2 knockedout (KO) cells, to resensitize the cell lines to doxorubicininduced cytotoxicity (Figure 5C) and to inhibit Pgp activity (Supplementary Figure S8). These results are consistent with the attribution of the effect of compounds 1,2 and 4 as being dependent on the modulation of CAXII activity. Ca12 KO cells had lower $\mathrm{pH}_{\mathrm{i}}$ (Figure 6A) and lower Pgp activity (Figure 6B) than wild-type cells. The addition of the $\mathrm{Na}^{+} / \mathrm{H}^{+}$ionophore monensin $(10 \mu \mathrm{M})$ increased the $\mathrm{pH}_{\mathrm{i}}$ of cal2 $\mathrm{KO}$ cells (Figure 6A) and the Pgp activity (Figure 6B) to values comparable with wildtype cells. Distinct from wild-type cells, doxorubicin did not increase the activity of Pgp in cal2 KO cells (Supplementary Figure S8), suggesting that the absence of CAXII hampered the substrate-dependent activation of Pgp. In contrast, tariquidar inhibited Pgp activity in both 
wild-type and cal2 KO cells (Supplementary Figure S8). These findings suggest that the absence or presence of CAXII does not influence the efficacy of tariquidar.

\section{CAXII inhibition reduces the growth of doxorubicin-resistant tumors in vivo}

To test the efficacy of CAXII inhibition in preclinical models of breast resistant tumors, we focused our attention on compound 1 , as it had achieved the most striking effect in terms of CAXII inhibition and doxorubicin-chemosensitizing effects in vitro.
We used the highly chemoresistant JC breast tumor model, which is refractory to doxorubicin (Figure 7A-7B). To maximize the drug delivery to the tumor, we injected compound 1 intratumorally, at $10 \mathrm{nM}(19 \mathrm{ng} / \mathrm{kg})$ and $1 \mu \mathrm{M}(1900 \mathrm{ng} / \mathrm{kg})$. The lower concentration falls in the range of the CAXII in vitro inhibition of compound $1\left(K_{\mathrm{i}}=\right.$ $1.0 \mathrm{nM}$ ); the higher concentration was selected to mitigate compound 1 clearance through lymphatic and blood vessels. Compound 1 has low mouse plasma stability $\left(\mathrm{t}_{1 / 2}=0.7 \mathrm{~h}\right)$ but good mouse liver microsome stability $\left(\mathrm{t}_{1 / 2}=134.8 \mathrm{~min}\right)$. At both dosages compound 1 had no effect on tumor growth when used alone, but when co-

A
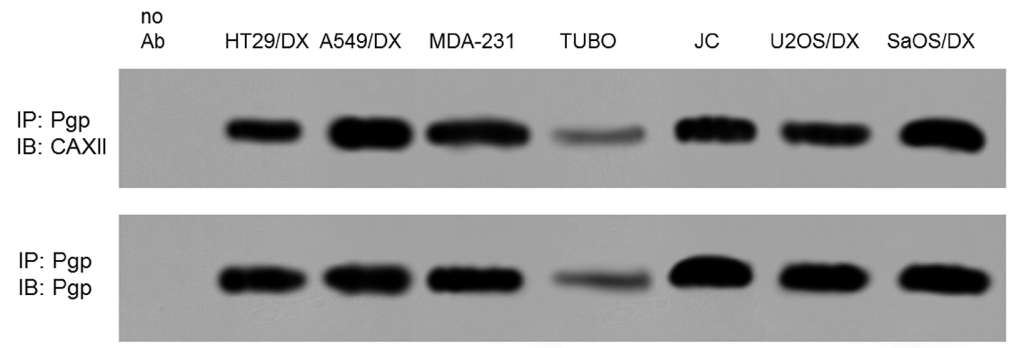

pancadherin

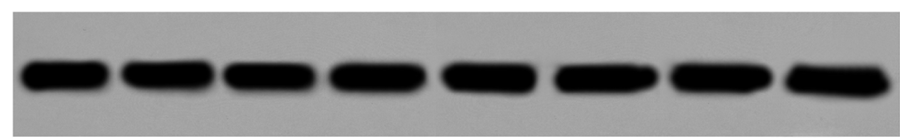

$\mathrm{B}$
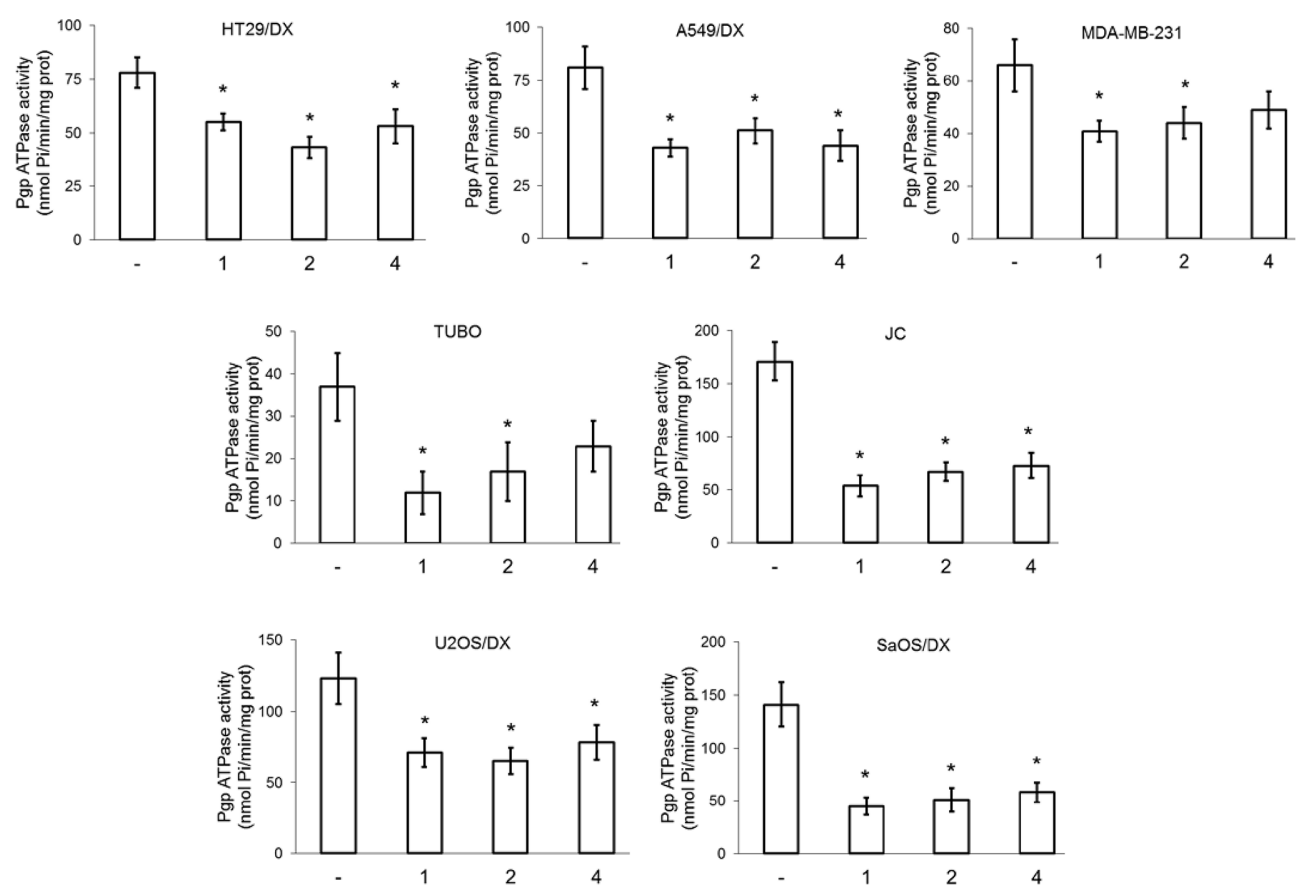

Figure 4: Effects of compound 1, 2 and 4 on Pgp activity. (A) Biotinylated plasma membrane-derived extracts from HT29/ DX, A549/DX, MDA-MB-231, TUBO, JC, U2OS/DX and SaOS/DX cells were immunoprecipitated (IP) with anti-Pgp antibody, then immunoblotted (IB) with anti-CAXII or anti-Pgp antibodies. Pancadherin level was used as control of equal protein loading. no Ab: A549/ DX sample immunoprecipitated without antibody. The figure is representative of one out of three experiments with similar results. (B) Cells were grown for $24 \mathrm{~h}$ in fresh medium (-) or in medium containing $5 \mathrm{nM}$ compounds 1,2 and 4 . The Pgp ATPase activity was measured spectrophotometrically on Pgp-rich vesicles extracted from membrane fractions. Data are presented as means \pm SD $(n=3)$. For all cell lines, versus untreated cells $(-):{ }^{*} p<0.002$. 

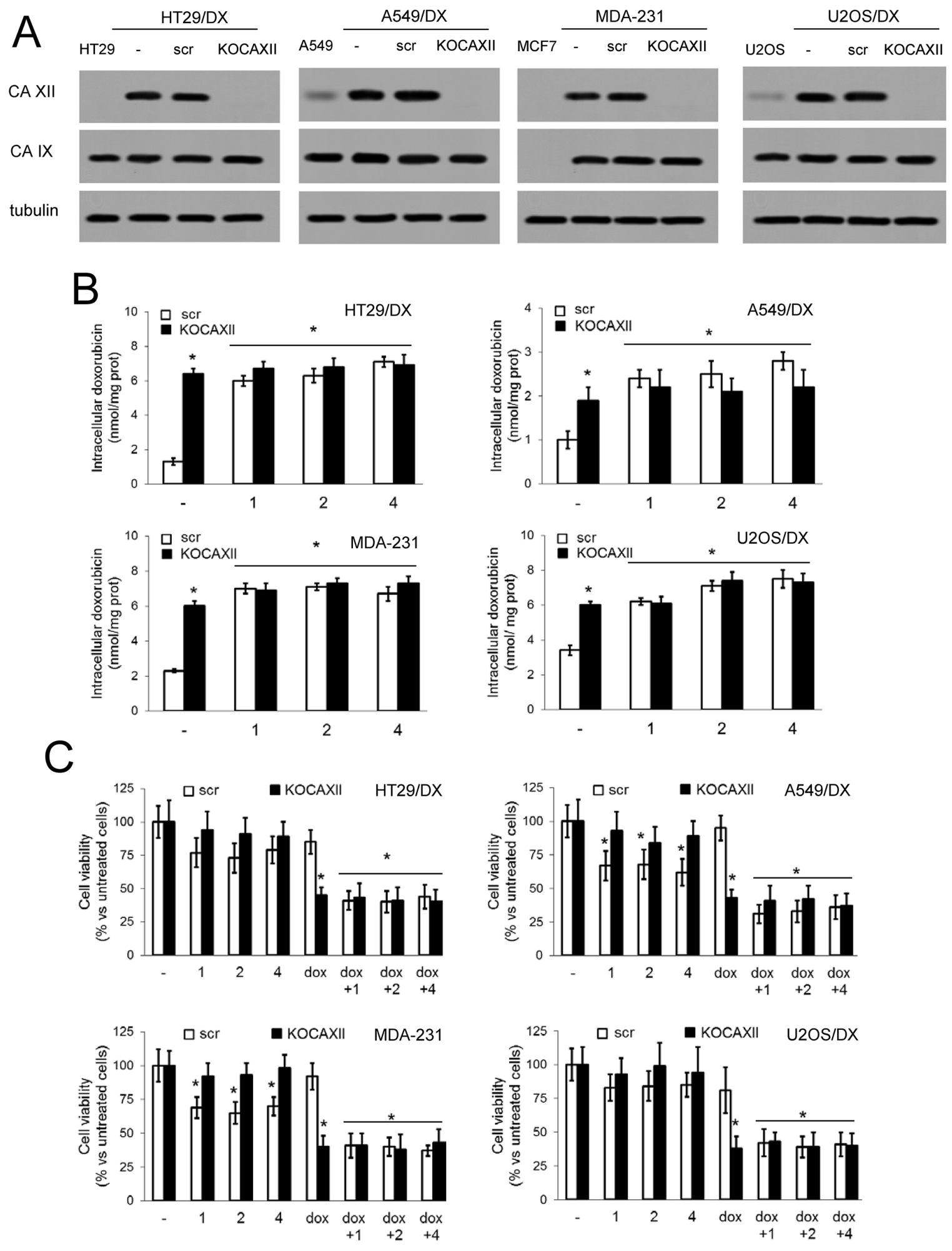

Figure 5: Effects of compound 1, 2 and 4 in ca12KO cancer cells. (A) HT29/DX, A549/DX, MDA-MB-231 and U2OS/DX cells were left untreated (-), treated with a not-targeting scrambled (scr) vector or with a cal2-targeting vector (KOCAXII), then immunoblotted for CAXII or CAIX. HT29, A549, MCF, U2OS cells were used as control of cells with low or undetectable levels of CAXII. $\beta$-tubulin level was used as control of equal protein loading. The figure is representative of one out of three experiments with similar results. (B) Cells treated as in A were incubated for $24 \mathrm{~h}$ with $5 \mu \mathrm{M}$ doxorubicin (-), alone or in the presence of $5 \mathrm{nM}$ compounds 1,2 or 4 , then the intracellular drug content was measured fluorimetrically. Data are presented as means $\pm \mathrm{SD}(n=4)$. For all cell lines, versus scr cells incubated with doxorubicin alone (-): ${ }^{*} p<0.001$. (C) Cells were incubated for $72 \mathrm{~h}$ in fresh medium (-), or in medium containing $5 \mu \mathrm{M}$ doxorubicin (dox), $5 \mathrm{nM}$ compounds 1, 2 or 4, alone or in combination, then stained with neutral red dye. The absorbance of viable cells was measured spectrophotometrically. Data are presented as means $\pm \mathrm{SD}(n=4)$. For all cell lines, versus scr untreated cells $(-): * p<0.01$. 
administered with doxorubicin it significantly increased the anti-proliferative effect of doxorubicin with $21 \%$ and $47 \%$ reduction in tumor volume at day 18 , when used at $19 \mathrm{ng} /$ $\mathrm{kg}$ and $1900 \mathrm{ng} / \mathrm{kg}$, respectively (Figure 7A-7B). At 1900 $\mathrm{ng} / \mathrm{kg}$ compound 1 produced tumor reduction similar to tariquidar (Figure 7A-7B). Worthy of note, at both dosages compound 1 did not induce liver, kidney or heart toxicity, according to the hematochemical parameters of the animals at the time of sacrifice (Supplementary Table S1). As expected, doxorubicin increased creatine phosphokinase (CPK) level, an index of cardiac damage,
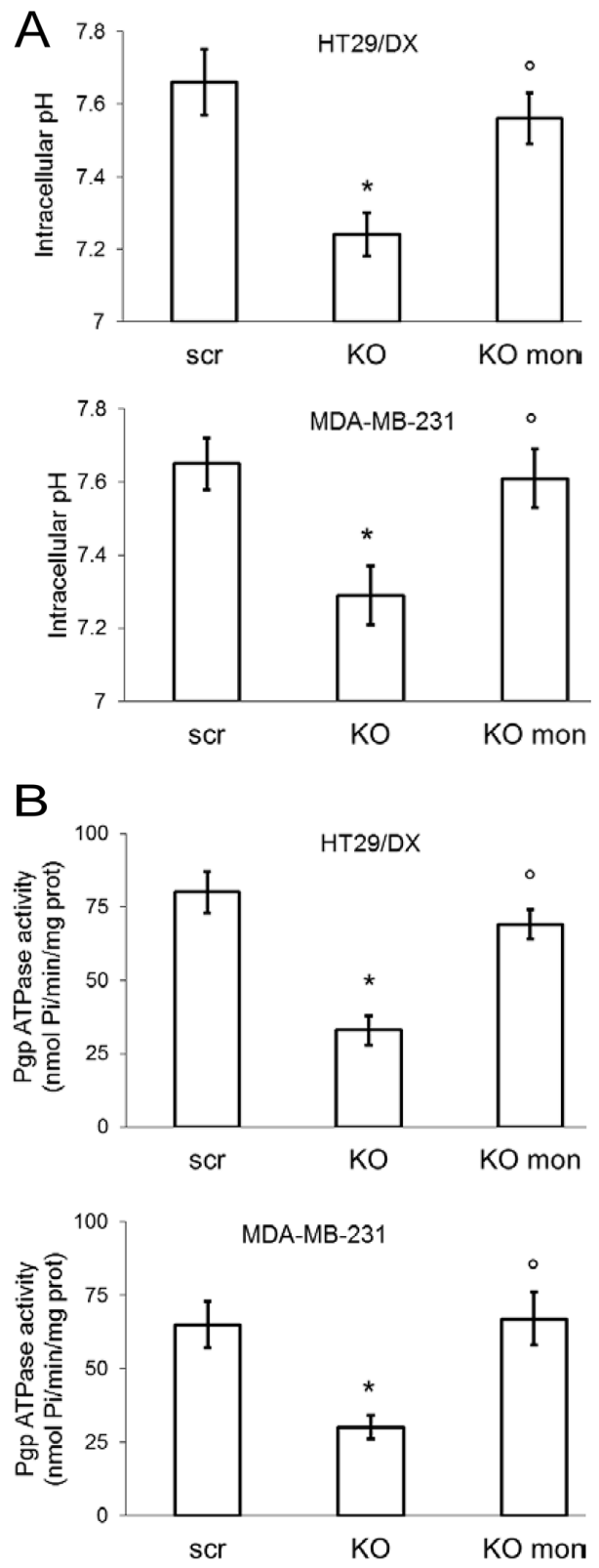

but compound 1 did not further increase this parameter in doxorubicin-treated animals (Supplementary Table S1).

\section{DISCUSSION}

In this work, we assessed a panel of CAXII inhibitors for their capacity to reverse doxorubicin resistance in MDR cancer cells that overexpress Pgp and resensitize cells to doxorubicin.

Our group has previously designed and synthesized carbohydrate-based CA inhibitors to preferentially inhibit
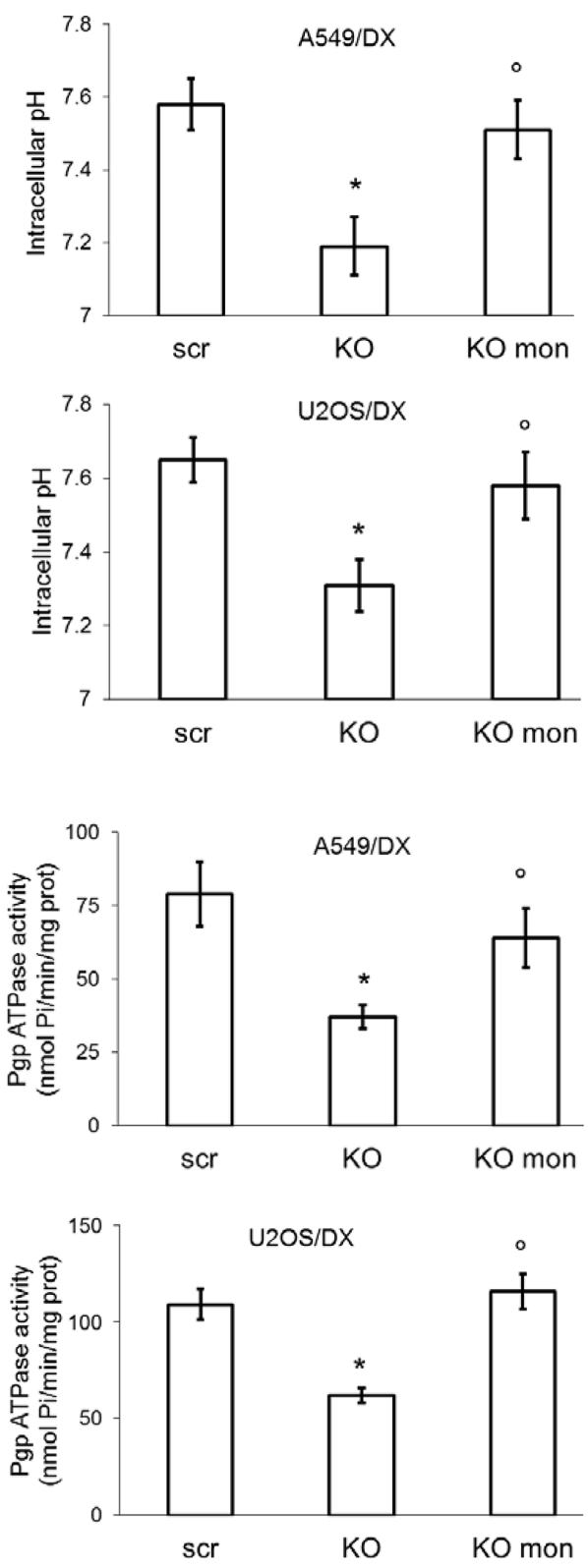

Figure 6: Effects of $\mathbf{p H}_{\mathrm{i}}$ rescue on Pgp activity of $\boldsymbol{c a 1 2}$ KO cells. HT29/DX, A549/DX, MDA-MB-231 and U2OS/DX cells were treated with a not-targeting scrambled (scr) vector or with a cal2-targeting vector (KO). (A) Cells were grown in fresh medium (-) or treated with monensin $\left(10 \mu \mathrm{M}\right.$ for $3 \mathrm{~h}$; mon). $\mathrm{pH}_{\mathrm{i}}$ measurement was performed by flow cytometry. Data are presented as means $\pm \mathrm{SD}$ $(n=4)$. For all cell lines, versus untreated scr cells $(-)$ : ${ }^{*} p<0.005$; vs KO cells: ${ }^{\circ} p<0.002$. (B) The Pgp ATPase activity was measured spectrophotometrically on Pgp-rich vesicles extracted from membrane fractions of cells incubated as reported in A. Data are presented as means $\pm \mathrm{SD}(n=3)$. For all cell lines, versus untreated scr cells $(-):{ }^{*} p<0.001$; vs KO cells: ${ }^{\circ} p<0.001$. 
cancer-associated CA isozymes (CAIX and CAXII) over intracellular CAs $[12,20,21]$. The combination of enzyme inhibition and physicochemical properties of the inhibitors was optimized to reduce passive membrane diffusion and favour selective inhibition of extracellular CAs over intracellular CAs. For this study a panel of eight compounds, $1-8$, were selected. The $\operatorname{cLog} P$ value of a compound is indicative of passive membrane permeability, with cLog $P$ values $<0$ expected to give compounds with minimal passive cell membrane permeability. Compounds with strong CAXII inhibition, with CAXII selectivity, and with $\mathrm{cLog} P$ values $<0$ are thus predicted to inhibit extracellular CA enzymes over intracellular CA enzymes and perform best in the cell-based models. The selection of compounds for this study was guided by these parameters.

Compounds 1, 2 and $4-8$ all have $K_{\mathrm{i}}<10 \mathrm{nM}$ for CAXII. These compounds also incorporate a polar monosaccharide or disaccharide moiety such that cLog $P$ values are in the range -3.17 to -4.94 . Compound 3 $(\mathrm{cLog} \mathrm{P}+1.40)$ is an acyl ester prodrug of compound 2 , unlike 2 it is expected that 3 will enter cells by passive membrane diffusion and then be converted to 2 by intracellular esterases. Consequently compounds 2 and 3 provide a 'drug/prodrug' pair where the observed activity of the 'drug' may be attributed to extracellular (2) and intracellular (3) localization of the inhibitor, respectively.
Compounds 1, 2 and 4 increased doxorubicin accumulation and efficacy in cancer cells that co-express CAXII and Pgp, with the same efficacy of tariquidar, one of the strongest third-generation Pgp inhibitors known [22], used in phase I and phase II clinical trials (https:// clinicaltrials.gov). The compounds also increased the intracellular accumulation of vinblastine and paclitaxel, Pgp substrates with alternate Pgp binding sites to doxorubicin [19]. This suggests that the CAXII inhibitors reduce Pgp activity, in a non-Pgp substrate specific manner. Additionally, doxorubicin and vinblastine are weakly basic drugs with increased protonation at acidic $\mathrm{pH}$, while paclitaxel is a non-ionizable drug that remains neutral at acidic $\mathrm{pH}$, hence the resensitizing effect of CAXII inhibitors is not limited to protonatable Pgp substrates. Furthermore, this effect was observed in tumor cells of different histological origins and species, suggesting that the compounds activity is independent of tumor type, species type or Pgp substrate type, requiring only a CAXII positive and Pgp positive phenotype. This phenotype may identify chemoresistant tumors that represent the best candidates for the co-treatment of Pgp substrate cancer chemotherapeutics with CAXII inhibitors. Since CAXII is usually poorly expressed in most healthy cells [5], the use of CAXII inhibitors, may provide a selective tumortargeting approach when administered with standard

A

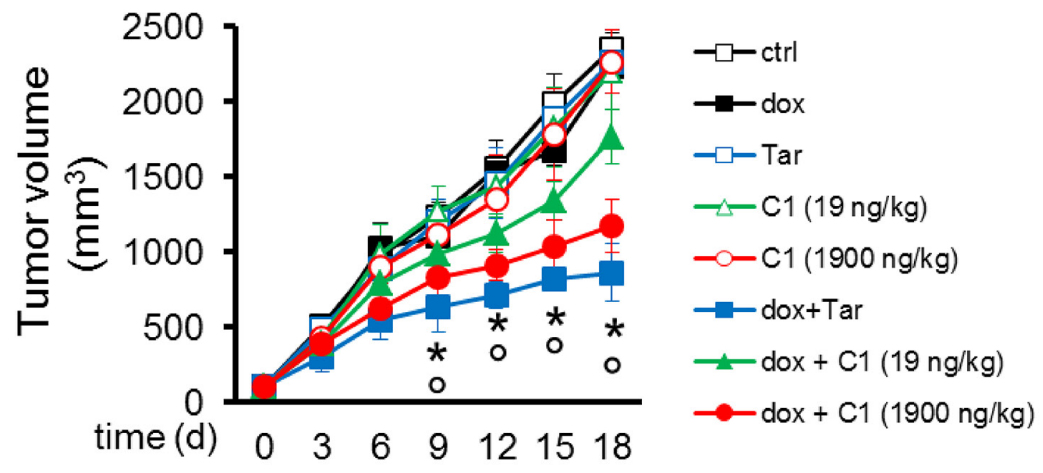

B
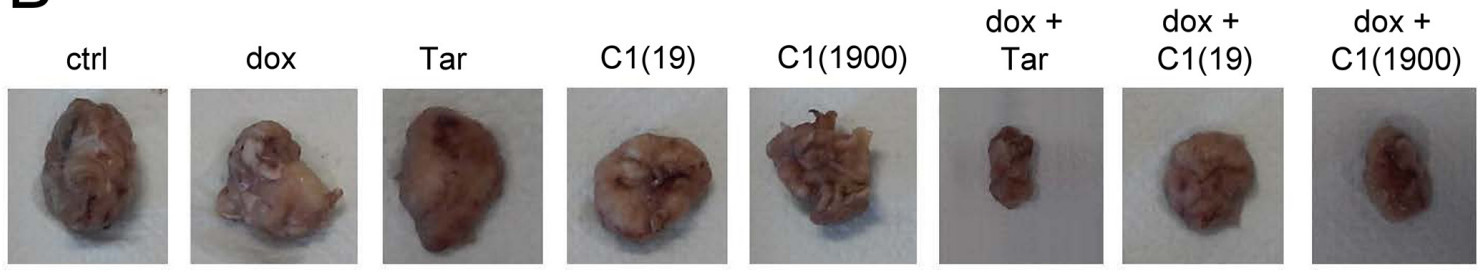

Figure 7: In vivo efficacy of compound 1 and doxorubicin against drug-resistant breast tumors. (A) Six week-old female BALB/c mice were inoculated s.c. with $1 \times 10^{6} \mathrm{JC}$ cells. When the tumor reached the volume of $100 \mathrm{~mm}^{3}$ (day 7), the mice were randomized into 8 groups (10 animals/group) and treated on days 0, 6 and 12 after the randomization as it follows: 1) control group, treated with $0.1 \mathrm{ml}$ saline solution intravenously (i.v.); 2) doxorubicin group, treated with $5 \mathrm{mg} / \mathrm{kg}$ doxorubicin i.v.; 3) tariquidar group, treated with $5 \mathrm{mg} / \mathrm{kg}$ tariquidar per os; 4) C1 19 group, treated with $19 \mathrm{ng} / \mathrm{kg}$ compound 1 (in $0.1 \mathrm{ml}$ saline solution; final concentration: $10 \mathrm{nM}$ ) intratumorally; 5) C1 1900 group, treated with $1900 \mathrm{ng} / \mathrm{kg}$ compound 1 (in $0.1 \mathrm{ml}$ saline solution; final concentration: $1 \mu \mathrm{M}$ ) intratumorally; 6) doxorubicin + tariquidar group, treated with $5 \mathrm{mg} / \mathrm{kg}$ doxorubicin i.v. and $5 \mathrm{mg} / \mathrm{kg}$ tariquidar per os; 7 ) doxorubicin $+\mathrm{C} 119$ group, treated with $5 \mathrm{mg} / \mathrm{kg}$ doxorubicin i.v. and $19 \mathrm{ng} / \mathrm{kg}$ compound 1 intratumorally; 8) doxorubicin $+\mathrm{C} 11900$ group, treated with $5 \mathrm{mg} / \mathrm{kg}$ doxorubicin i.v. and $1900 \mathrm{ng} / \mathrm{kg}$ compound 1 intratumorally. Tumor growth was monitored by caliper measure. Data are presented as means \pm SD. Dox + Tar/dox + C1 19/dox + C1 1900 groups versus ctrl group: * $p<0.05$; dox + Tar/dox + C1 0.5/dox + C1 50 groups versus dox group: ${ }^{\circ} p<0.005$. (B) Photographs of representative tumors from each treatment group after mice sacrifice. 
chemotherapeutic drugs to patients with drug resistant tumors. Indeed, our compounds were not cytotoxic in epithelial and fibroblasts cells, that had undetectable levels of CAXII. The lack of efficacy of compounds 1, 2 and 4 in cal $2 \mathrm{KO}$ cancer cells further demonstrated that CAXII inhibition is the critical mechanism of action in reversing doxorubicin resistance. Similarly, the lack of efficacy of the compounds in CAXII-negative cells overexpressing Pgp suggests that the increased doxorubicin retention is not due to a direct inhibition of Pgp, but it is a consequence of CAXII inhibition.

CAIX has been correlated with an aggressive tumor phenotype $[5,11]$ and resistance against doxorubicin in breast cancer tumors [23]. However, in our in vitro screening the efficacy of compounds 1, 2 and 4 in increasing doxorubicin accumulation and cytotoxicity was independent of the expression of CAIX. These findings correlate with previous data that demonstrated silencing of CAIX in doxorubicin-resistant cells did not impact on drug-resistance, while silencing of CAXII reversed the drug-resistant phenotype [16].

CAXII is critical for maintaining normal $\mathrm{pH}_{\mathrm{i}}$ in cancer cells $[1,11]$. We hypothesize that the inhibition of CAXII alters the membrane microenvironment where Pgp works, impairing the optimal conditions for its function as an efflux pump. Chemoresistant cells have a slightly alkaline $\mathrm{pH}_{\mathrm{i}}$ that contributes to the maintenance of their drug-resistant phenotype [24]. Isolated Pgp has consistent basal activity across the $\mathrm{pH}$ range 6.2 to 7.6 (at $37^{\circ} \mathrm{C}$ ) [25], which is compatible with the $\mathrm{pH}_{\mathrm{i}}$ of the doxorubicin-resistant cells analyzed (ranging from 7.45 to $7.64 \mathrm{pH}$ units). We previously reported that the treatment with the classical CAXII inhibitor acetazolamide (AZA), as well as CAXII silencing, lowered the $\mathrm{pH}_{\mathrm{i}}$ of doxorubicin-resistant colon cancer cells and reduced Pgp activity [16]. Compounds 1, 2 and 4 decreased $\mathrm{pH}_{\mathrm{H}}$ ( 1 by 0.24 units, 2 by 0.12 units, and 4 by 0.06 units). Similarly cal2 KO cells had lower $\mathrm{pH}_{\mathrm{i}}$ than wild-type cells. This decrease was paralleled by a reduction in Pgp ATPase activity. Of note, when $\mathrm{pH}_{\mathrm{i}}$ in cal2 $\mathrm{KO}$ cells was increased to the same $\mathrm{pH}$ value of wild-type cells with monensin, Pgp activity also increased. These results suggest that the increased $\mathrm{pH}_{\mathrm{i}}$ maintained by CAXII in resistant cells is critical to maintain optimal Pgp activity. The lower $\mathrm{pH}_{\mathrm{i}}$ produced by CAXII inhibition reduces Pgp activity, resulting in increased intracellular retention of doxorubicin, vinblastine and paclitaxel. Although we did not measure the $\mathrm{pH}$ within the lipid microenvironment where Pgp and CAXII operate in close proximity, we may infer that the inhibition of CAXII reduced the $\mathrm{pH}$ in the plasma membrane microenvironment even more than in whole cell, markedly decreasing Pgp activity. Notably, compounds 1, 2 and 4 are all expected to have low cell membrane passive diffusion and thus inhibit CAXII. By contrast, compound 3, a lipophilic ester 'prodrug' of 2 and expected to yield compound 2 in the intracellular environment following esterase processing, was devoid of efficacy. These data further suggest that it is inhibition of extracellular facing CAXII (and not intracellular CAs) that may be attributed to the reversal of drug resistance.

Compared with the classical CAXII inhibitor AZA, compounds 1, 2 and 4 offer the advantage of higher selectivity toward CAXII, lower $K_{\mathrm{i}}$ values and reduced lipophilicity. These attributes render them promising candidates to be tested in vivo, using the Pgp-positive and doxorubicin-resistant JC model [26, 27]. We selected compound 1 for an in vivo study as this compound had the maximal chemosensitizing effect in vitro.

To avoid compound related metabolism or clearance and maximise tumor delivery, we administered 1 intratumorally. Either a dosage of 1 around the CAXII $K_{\mathrm{i}}$ or a 100 -fold higher dosage, to counteract compound clearance through lymphatic and blood vessels, significantly reduced tumor growth when coadministered with doxorubicin. Since the compound alone (i.e. without co-administration of doxorubicin) did not reduce tumor growth, such effect was likely due to the increased retention of doxorubicin within cancer cells. These data suggest that compound 1 effectively reverses the resistance to doxorubicin in vivo to resensitize these resistant cells to doxorubicin treatment. The sensitization efficacy was comparable to the third-generation Pgp inhibitor tariquidar. Moreover, compound 1, either alone or with doxorubicin, did not elicit liver or kidney toxicity, or increase the cardiac damage induced by doxorubicin (an anthracycline), according to the hematochemical parameters of the animals. We propose that the indirect mechanism of action of CAXII inhibitors to reduce Pgp activity voids the usual in vivo toxicity associated with direct Pgp inhibition. Additionally, as CA inhibitors have been a mainstay of human clinical intervention for several decades (more than 25 clinically approved CA inhibitors) this drug class has a recorded safety profile [28]. Moreover, mammalian CAs belong to the $\alpha$-CA family, with murine CAXII expressed in the large intestine and kidney similarly to human CAXII $[29,30]$. Given the significant chemosensitizing effect of compound 1, we speculate that the dosage of doxorubicin- if co-administered with compound 1 (or other selective small molecule CAXII inhibitors) -may even be reduced while retaining its antitumor efficacy yet limiting doxorubicin associated cardiotoxicity.

In summary, our work suggests that CAXII inhibitors are potent chemosensitizing agents in tumors overexpressing both CAXII and Pgp. Given the prevalent expression of CAXII in tumor tissues and the high selectivity of our inhibitors towards this CA isoform, our compounds appear as promising tumor-selective agents. These results may be a turning point toward new treatments based on a combination of a CAXII selective inhibitor with chemotherapeutic drugs, where the chemotherapeutic drugs alone are ineffective in treating Pgp-positive (i.e. MDR) tumors. This approach may be particularly beneficial for patients with tumors that co- 
express CAXII and Pgp, a typical feature of aggressive and chemoresistant tumors. Furthermore, neo-adjuvant protocols based on anthracyclines are currently used in the treatment of breast cancer to improve patient outcomes, with the purpose to reduce tumor mass and allow a more conservative surgery [31]. In a translational perspective our study may provide the rational basis for a new neoadjuvant combinatorial therapy for breast tumors to enhance the effectiveness of cytotoxic chemotherapeutic drugs, i.e. the loco-regional administration of a CAXII inhibitor as a chemosensitizer agent followed by systemic administration of doxorubicin. To the best of our knowledge, such an approach has not been reported. The expression of CAIX, the more well studied cancerassociated CA isozyme, did not influence the effects of the compounds on the intracellular doxorubicin accumulation in all cell lines tested. We recommend that future studies involving CAs in cancer concomitantly examine CAIX and CAXII expression, rather than only CAIX, to better inform the interpretation of experimental findings.

\section{MATERIALS AND METHODS}

\section{Materials}

The plasticware for cell cultures was obtained from Falcon (Becton Dickinson, Franklin Lakes, NJ). The electrophoresis reagents were obtained from BioRad Laboratories (Hercules, CA). The protein content of cell lysates was assessed with the BCA kit from Sigma Chemicals Co. (St. Louis, MO). Tariquidar dihydrochloride was from Tocris Bioscience (Bristol, UK). Unless specified otherwise, all reagents were purchased from Sigma Chemicals Co.

\section{CAXII inhibitors}

The synthesis and structural characterization of carbohydrate-based sulfamates (1-4) [32, 33] and sulfonamides (5-8) [12] has been fully described previously by us. The chemical structure of the compounds is reported in Figure 1.

\section{CA inhibition}

The inhibition of CA I, II, IX and XII by test inhibitors (1-8) has been previously reported by us $[12,32$, 33]. Inhibition data and isozyme selectivity values are reported in Table 1. Briefly, a stopped-flow instrument was used to monitor the $\mathrm{CA}$-catalyzed $\mathrm{CO}_{2}$ hydration reaction for a period of 10-100 $\mathrm{s}$ with phenol red as a $\mathrm{pH}$ indicator. Saturated $\mathrm{CO}_{2}$ solutions in water at $20^{\circ} \mathrm{C}$ were used as substrate, while the recombinant CA protein was prepared in Hepes buffer $(10 \mathrm{mM}, \mathrm{pH} 7.5)$ with added $\mathrm{NaClO}_{4}(0.1 \mathrm{M})$ to maintain a constant the ionic strength. The inhibitor and enzyme solutions were preincubated for $15 \mathrm{~min}$ at room temperature prior to assay in order to allow for the formation of the enzyme-inhibitor complex. The inhibition constants were obtained by nonlinear least-squares methods using PRISM 3. The curve fitting algorithm allowed us to obtain the $\mathrm{IC}_{50}$ values, from which $K_{\mathrm{i}}$ values were calculated by using the Cheng-Prusoff equation.

\section{Cell lines}

Human colon cancer HT29 cells, lung cancer A549 cells, breast cancer MCF-7, SKBR3, T74D and MDAMB-231 cells, osteosarcoma U2OS and SaOS cells, murine chemoresistant JC cells, not-transformed human colon epithelial CCD-Co-18 cells, lung epithelial BEAS2B cells, breast epithelial MCF10A cells were purchased from ATCC (Manassas, VA). Murine chemoresistant TUBO cells were a kind gift of Prof. Federica Cavallo, Department of Molecular Biotechnology and Health Sciences, University of Torino, Italy. Not-transformed human fibroblasts were a kind gift of Prof. Franco Novelli, Department of Molecular Biotechnology and Health Sciences, University of Torino, Italy. Human HT29/DX and A549/DX were generated by stepwise selection in medium with increasing concentration of doxorubicin, as reported by us [34], and maintained in culture medium with a final concentration of $200 \mathrm{nM}$ and 100 $\mathrm{nM}$ doxorubicin, respectively. U2OS/DX and SaOS/DX cells were generated with a similar procedure [35] and maintained in culture medium with a final concentration of $1 \mu \mathrm{M}$ doxorubicin. The expression levels of CAXII, CAIX and Pgp were measured by immunoblotting (see below): the results are reported in the Supplementary Figure S1. All cell lines were authenticated by microsatellite analysis, using the PowerPlex kit (Promega Corporation, Madison, WI; last authentication: June 2016). Cells were maintained in media supplemented with $10 \% \mathrm{v} / \mathrm{v}$ fetal bovine serum, $1 \% \mathrm{v} / \mathrm{v}$ penicillinstreptomycin, 1\% v/v L-glutamine.

\section{Immunoblotting}

For whole cell lysates, the cells were rinsed with ice-cold lysis buffer (50 mM, Tris, $10 \mathrm{mM}$ EDTA, 1\% v/v Triton-X100), supplemented with the protease inhibitor cocktail set III ( $80 \mu \mathrm{M}$ aprotinin, $5 \mathrm{mM}$ bestatin, $1.5 \mathrm{mM}$ leupeptin, $1 \mathrm{mM}$ pepstatin; Calbiochem, San Diego, CA), $2 \mathrm{mM}$ phenylmethylsulfonyl fluoride and $1 \mathrm{mM} \mathrm{Na}_{3} \mathrm{VO}_{4}$, then sonicated and centrifuged at $13,000 \times \mathrm{g}$ for $10 \mathrm{~min}$ at $4^{\circ} \mathrm{C} .20 \mu \mathrm{g}$ protein extracts were subjected to SDS-PAGE and probed with the following antibodies: anti-CAXII (Abcam, Cambridge, UK), anti-CAIX (Novus Biologicals, Littleton, CO), anti-Pgp (C219, Calbiochem), anti- $\beta$ tubulin (Santa Cruz Biotechnology Inc., Santa Cruz, CA), followed by a peroxidase-conjugated secondary antibody (Bio-Rad Laboratories). The membranes were washed with Tris-buffered saline-Tween $0.1 \% \mathrm{v} / \mathrm{v}$ solution, and the proteins were detected by enhanced chemiluminescence (Bio-Rad Laboratories). Plasma membrane-associated 
proteins were evaluated in biotinylation assays, using the Cell Surface Protein isolation kit (Thermo Fisher Scientific Inc., Waltham, MA), as previously reported [36]. An anti-pancadherin antibody (Santa Cruz Biotechnology Inc.) was used to confirm equal protein loading. In coimmunoprecipitation experiments, $100 \mu \mathrm{g}$ of plasma membrane-associated proteins were immunoprecipitated with the anti-Pgp antibody, using the PureProteome protein A and protein G Magnetic Beads (Millipore, Billerica, MA). The immunoprecipitated proteins were separated by SDSPAGE and probed with anti-CAXII or anti-Pgp antibodies, followed by a peroxidase-conjugated secondary antibody.

\section{Pgp overexpression}

To generate the Pgp-positive MCF7 and SKBR3 cells, the pHa vector containing the complete $m d r 1$ cDNA was purchased from Addgene (Cambridge, MA) and subcloned into pCDNA3 vector (Invitrogen Life Technologies, Milan, Italy) as described [37].

\section{Chemotherapeutic drug accumulation}

Doxorubicin content was measured fluorimetrically as detailed previously by us [34]. Vinblastine and paclitaxel accumulation were measured by labelling cells with $1 \mu \mathrm{Ci}\left[{ }^{3} \mathrm{H}\right]$-vinblastine sulphate (PerkinElmer, Waltham, MA) and $\left[{ }^{3} \mathrm{H}\right]$-paclitaxel (Moravek Inc., Brea, CA). Cells were washed twice with PBS, detached with trypsin and sonicated. The intracellular drug content was measured by liquid scintillation. The results were expressed as nmol drug/mg cell proteins, according to titration curves previously set.

\section{Cell viability}

Cell viability was evaluated by measuring the percentage of cells stained with neutral red dye, as reported previously [38]. The viability of untreated cells was considered $100 \%$; the results were expressed as percentage of viable cells in each experimental condition versus untreated cells. To determine the $\mathrm{IC}_{50}$ of doxorubicin in CAXII inhibitor treated cells $5 \times 10^{5}$ cells, with concentrations of doxorubicin (ranging from $1 \mathrm{nM}$ to $1 \mathrm{mM}$ ), were incubated in the absence or presence of $5 \mathrm{nM}$ of each CAXII inhibitor for $72 \mathrm{~h}$. The inhibitory concentration $50\left(\mathrm{IC}_{50}\right)$ is defined as the concentration of doxorubicin that kills $50 \%$ of cells. The resistance factor (Rf) was calculated as the ratio between mean $\mathrm{IC}_{50}$ in cells treated with CAXII inhibitors and mean $\mathrm{IC}_{50}$ in cells treated with tarquidar.

\section{Pgp ATPase activity}

The assay was performed on Pgp-enriched membrane vesicles as detailed in [39]. Verapamil $(10 \mu \mathrm{M})$ was added to the reaction mix to achieve a maximal activation of the Pgp ATPase activity. Results were expressed as nmol hydrolyzed phosphate (Pi)/min/mg proteins, according to the titration curve previously prepared.

\section{$\mathrm{pH}_{\mathrm{i}}$ measurement}

$\mathrm{pH}_{\mathrm{i}}$ was measured by incubating whole cells with $5 \quad \mu \mathrm{M} \quad 2^{\prime}, 7^{\prime}$-bis-(2-carboxyethyl)-5-(and-6)carboxyfluorescein acetoxymethyl ester for $15 \mathrm{~min}$ at $37^{\circ} \mathrm{C}$ and reading the intracellular fluorescence by a FACSCalibur flow cytometer (Becton Dickinson). The intracellular fluorescence was converted into $\mathrm{pH}$ units according to a titration curve, as described previously [24].

\section{Ca12 knockout}

$5 \times 10^{5}$ cells were transduced with $1 \mu \mathrm{g}$ RNA vector (CRISPR pCas guide vector) ca12 or $1 \mu \mathrm{g}$ not-targeting vector, mixed with $1 \mu \mathrm{g}$ donor DNA vector (Origene, Rockville, MD), following the manufacturer's instructions. Stable KO cells were selected in complete medium containing $1 \mu \mathrm{g} / \mathrm{ml}$ puromycin for three weeks. Knockout efficacy was evaluated by immunoblotting, as reported above. Cell viability was evaluated by neutral red staining: ca12 KO cells had the same viability than parental cells (data not shown).

\section{In vivo tumor growth}

To evaluate the anti-tumor efficacy of CAXII inhibitors, we injected subcutaneously $1 \times 10^{6} \mathrm{JC}$ cells, a mammary cancer cell line known for its high expression of Pgp [26] and its strong refractoriness to doxorubicin [27], mixed with $100 \mu \mathrm{L}$ Matrigel, in syngeneic 6 weekold female BALB/c mice (weight: $20 \mathrm{~g} \pm 1.3$; Charles River Laboratories Italia, Calco). Animals were housed (5 per cage) under $12 \mathrm{~h}$ light/dark cycles, with food and drinking provided ad libitum. Tumor growth was measured daily by caliper and calculated according to the equation $\left(\mathrm{L} \times \mathrm{W}^{2}\right) / 2$, where $\mathrm{L}=$ tumor length, $\mathrm{W}=$ tumor width. When the tumor reached a volume of $100 \mathrm{~mm}^{3}$ (day 7 after injection), the mice were randomized into 8 groups (10 animals/group) and treated on days 0, 6 and 12 after the randomization as it follows: 1) control group, treated with $0.1 \mathrm{ml}$ saline solution intravenously (i.v.); 2) doxorubicin group, treated with $5 \mathrm{mg} / \mathrm{kg}$ doxorubicin i.v.; 3) tariquidar group, treated with $5 \mathrm{mg} / \mathrm{kg}$ tariquidar per os; 4) C1 19 group, treated with $19 \mathrm{ng} / \mathrm{kg}$ compound 1 (in $0.1 \mathrm{ml}$ saline solution; final concentration: $10 \mathrm{nM}$ ) intratumorally; 5) C1 1900 group, treated with $1900 \mathrm{ng} / \mathrm{kg}$ compound 1 (in $0.1 \mathrm{ml}$ saline solution; final concentration: $1 \mu \mathrm{M}$ ) intratumorally; 6) doxorubicin + tariquidar group, treated with $5 \mathrm{mg} / \mathrm{kg}$ doxorubicin i.v. and $5 \mathrm{mg} / \mathrm{kg}$ tariquidar $\mathrm{per}$ os; 7) doxorubicin + C1 19 group, treated with $5 \mathrm{mg} / \mathrm{kg}$ doxorubicin i.v. and $19 \mathrm{ng} / \mathrm{kg}$ compound 1 intratumorally; 8) doxorubicin + C1 1900 group, treated with $5 \mathrm{mg} / \mathrm{kg}$ doxorubicin i.v. and $1900 \mathrm{ng} / \mathrm{kg}$ compound 1 intratumorally. 
Tumor volumes were monitored daily by caliper and animals were euthanized by injecting zolazepam $(0.2 \mathrm{ml} /$ $\mathrm{kg}$ ) and xylazine (16 mg/kg) intramuscle (i.m.) at day 18 . Tumors were excised and photographed immediately after mice sacrifice. The hematochemical parameters lactate dehydrogenase (LDH), aspartate aminotransferase (AST), alanine aminotransferase (ALT), alkaline phosphatase (AP), creatinine, CPK were measured on $0.5 \mathrm{ml}$ of blood collected immediately after mice sacrifice, using the respective kits from Beckman Coulter Inc. (Miami, FL). Animal care and experimental procedures were approved by the Bio-Ethical Committee of the Italian Ministry of Health (\#122/2015-PR).

\section{Pharmacokinetics}

Plasma stability (mouse) and liver microsome metabolic stability (mouse) were measured by the Biopharmacy Laboratory, Shanghai Institute of Materia Medica, Chinese Academy of Sciences.

\section{Statistical analysis}

All data in the text and figures are provided as means $\pm \mathrm{SD}$. The results were analyzed by a one-way analysis of variance (ANOVA) and Tukey's test, using Statistical Package for Social Science (SPSS) software (IBM SPSS Statistics v.19). $p<0.05$ was considered significant.

\section{ACKNOWLEDGMENTS}

We are grateful to Mr. Costanzo Costamagna, Department of Oncology, University of Torino, for technical assistance.

\section{CONFLICTS OF INTEREST}

The authors of this manuscript have no conflicts of interest to declare.

\section{GRANT SUPPORT}

This work was supported by the Italian Association for Cancer Research (IG15232) and Italian Ministry of University and Research (FIRB 2012, grant RBFR12SOQ1) to CR; and the Australian Research Council (FT10100185) to S-AP. The funding institutions had no role in the study design, in the data collection and analysis, in the manuscript writing. JK is recipient of a fellowship from "Fondazione Umberto Veronesi". ICS is recipients of PhD scholarship from the Italian Institute for Social Security (INPS). GR was supported by funds from Griffith University.

\section{REFERENCES}

1. Frost SC. Physiological functions of the alpha class of carbonic anhydrases. Subcell Biochem. 2014; 75:9-30.
2. Kivelä A, Parkkila S, Saarnio J, Karttunen TJ, Kivelä J, Parkkila AK, Waheed A, Sly WS, Grubb JH, Shah G, Türeci O, Rajaniemi H. Expression of a novel transmembrane carbonic anhydrase isozyme XII in normal human gut and colorectal tumors. Am J Pathol. 2000; 156:577-584.

3. Hynninen P, Vaskivuo L, Saarnio J, Haapasalo H, Kivelä J, Pastoreková S, Pastorek J, Waheed A, Sly WS, Puistola U, Parkkila S. Expression of transmembrane carbonic anhydrases IX and XII in ovarian tumours. Histopathology. 2006; 49:594-602.

4. Rafalko A, Iliopoulos O, Fusaro VA, Hancock W, Hincapie M. Immunoaffinity enrichment and liquid chromatographyselected reaction monitoring mass spectrometry for quantitation of carbonic anhydrase 12 in cultured renal carcinoma cells. Anal Chem. 2010; 82 8998-9005.

5. Monti SM, Supuran CT, De Simone G. Anticancer carbonic anhydrase inhibitors: a patent review (2008 - 2013). Expert Opin Ther Pat. 2013; 23:737-749.

6. Zheng B, Liu J, Gu J, Lu Y, Zhang W, Li M, Lu Hui. A three-gene panel that distinguishes benign from malignant thyroid nodules. Int J Cancer. 2015; 136:1646-1654.

7. Kobayashi M, Matsumoto $\mathrm{T}$, Ryuge $\mathrm{S}$, Yanagita $\mathrm{K}$, Nagashio R, Kawakami Y, Goshima N, Jiang S-X, Saegusa M, Iyoda A, Satoh Y, Masuda N, Sato Y. CAXII is a sero-diagnostic marker for lung cancer. Plos ONE. 2012; 7:e33952.

8. Haapasalo J, Hilvo M, Nordfors K, Haapasalo $H$, Parkkila S, Hyrskyluoto A, Rantala I, Waheed A, Sly WS, Pastorekova S, Pastorek J, Parkkila AK. Identification of an alternatively spliced isoform of carbonic anhydrase XII in diffusely infiltrating astrocytic gliomas. Neuro Oncol. 2008; 10:131-138.

9. Chien MH, Ying TH, Hsieh YH, Lin CH, Shih CH, Wei LH, Yang SF. Tumor-associated carbonic anhydrase XII is linked to the growth of primary oral squamous cell carcinoma and its poor prognosis. Oral Oncol. 2012; 48:417-423.

10. Ochi F, Shiozaki A, Ichikawa, D, Fujiwara H, Nakashima S, Takemoto K, Kosuga T, Konishi H, Komatsu S, Okamoto K, KIshimoto M, Marunaka Y, Otsuji E. Carbonic anhydrase $\mathrm{XII}$ as an independent prognostic factor in advanced esophageal squamous cell carcinoma. J Cancer. 2015; 6:922-929.

11. Chiche J, Ilc K, Laferrière J, Trottier E, Dayan F, Mazure NM, Brahimi-Horn MC, Pouysségur J. Hypoxia-inducible carbonic anhydrase IX and XII promote tumor cell growth by counteracting acidosis through the regulation of the intracellular pH. Cancer Res. 2009; 69:358-368.

12. Morris JC, Chiche J, Grellier C, Lopez M, Bornaghi LF, Maresca A, Supuran CT, Pouysségur J, Poulsen SA. Targeting hypoxic tumor cell viability with carbohydratebased carbonic anhydrase IX and XII inhibitors. J Med Chem. 2011; 54:6905-6918.

13. Parkkila S, Parkkila AK, Saarnio J, Kivelä J, Karttunen TJ, Kaunisto K, Waheed A, Sly WS, Türeci O, Virtanen I, Rajaniemi H. Expression of the membrane-associated 
carbonic anhydrase isozyme XII in the human kidney and renal tumors. J Histochem Cytochem. 2000; 48:1601-1608.

14. Gondi G, Mysliwietz J, Hulikova A, Jen JP, Swietach P, Kremmer E, Zeidler R. Antitumor efficacy of a monoclonal antibody that inhibits the activity of cancer-associated carbonic anhydrase XII. Cancer Res. 2013; 73:6494-6503.

15. Gieling RG, Babur M, Mamnani L, Burrows N, Telfer BA, Carta F, Winum JY, Scozzafava A, Supuran CT, Williams KJ. Antimetastatic effect of sulfamate carbonic anhydrase IX inhibitors in breast carcinoma xenografts. J Med Chem. 2012; 55:5591-5600.

16. Kopecka J, Campia I, Jacobs A, Frei AP, Ghigo D, Wollscheid B, Riganti C. Carbonic anhydrase XII is a new therapeutic target to overcome chemoresistance in cancer cells. Oncotarget. 2015; 6:6776-6793. doi: 10.18632/ oncotarget.2882.

17. Gottesman MM, Fojo T, Bates SE. Multidrug resistance in cancer: role of ATP-dependent transporters. Nat Rev Cancer. 2002; 2:48-58.

18. Brózik A, Hegedüs C, Erdei Z, Hegedus T, Özvegy-Laczka C, Szakács G, Sarkadi B. Tyrosine kinase inhibitors as modulators of ATP binding cassette multidrug transporters: substrates, chemosensitizers or inducers of acquired multidrug resistance? Expert Opin Drug Metab Toxicol. 2011; 7:623-642.

19. Martin C, Berridge G, Higgins CF, Mistry P, Charlton P, Callaghan R. Communication between multiple drug binding sites on P-glycoprotein. Mol Pharmacol. 2000; 58: 624-632.

20. Lopez M, Bornaghi LF, Innocenti A, Vullo D, Charman SA, Supuran CT, Poulsen S.-A. Sulfonamide Linked Neoglycoconjugates - A New Class of Inhibitors for Cancer-Associated Carbonic Anhydrases. J Med Chem. 2010; 53:2913-2926.

21. Moeker J, Mahon BP, Bornaghi LF, Vullo D, Supuran CT, McKenna R, Poulsen SA. Structural insights into carbonic anhydrase IX isoform specificity of carbohydrate-based sulfamates. J Med Chem. 2014; 57:8635-8645.

22. Fox E, Bates SE. Tariquidar (XR9576): a P-glycoprotein drug efflux pump inhibitor. Expert Rev Anticancer Ther. 2007; 7:447-459.

23. Betof AS, Rabbani ZN, Hardee ME, Kim SJ, Broadwater G, Bentley RC, Snyder SA, Vujaskovic Z, Oosterwijk E, Harris LN, Horton JK, Dewhirst MW, Blackwell KL. Carbonic anhydrase IX is a predictive marker of doxorubicin resistance in early-stage breast cancer independent of HER2 and TOP2A amplification. Br J Cancer. 2012; 106: 916-922.

24. Miraglia E, Viarisio D, Riganti C, Costamagna C, Ghigo D, Bosia A. $\mathrm{Na}^{+} / \mathrm{H}^{+}$exchanger activity is increased in doxorubicin-resistant human colon cancer cells and its modulation modifies the sensitivity of the cells to doxorubicin. Int J Cancer. 2005; 115:924-929.

25. Aänismaa P, Seelig A. P-Glycoprotein kinetics measured in plasma membrane vesicles and living cells. Biochemistry. 2007; 46:3394-3404.

26. Lee B, French K, Zhuang Y, Smith C. Development of a syngeneic in vivo tumor model and its use in evaluating a novel p-glycoprotein modulator, pgp-4008. Oncol Res. 2003; 14:49-60.

27. Riganti C, Gazzano E, Gulino GR, Volante M, Ghigo D, Kopecka J. Two repeated low doses of doxorubicin are more effective than one single high dose against tumors overexpressing P-glycoprotein. Cancer Lett 2015; 360: 219-226.

28. Supuran CT. Carbonic anhydrases: novel therapeutic applications for inhibitors and activators. Nat Rev Drug Discov. 2008; 7:168-181.

29. Halmi P, Lehtonen J, Waheed A, Sly WS, Parkkila S. Expression of hypoxia-inducible, membrane-bound carbonic anhydrase isozyme XII in mouse tissues. Anat Rec. 2004; 277A:171-177.

30. Pan P-W, Rodriguez A, Parkkila S. A systematic quantification of carbonic anhydrase transcripts in the mouse digestive system. BMC Molecular Biology 2007; 8:e22.

31. Haddad TC, Goetz MP. Landscape of neoadjuvant therapy for breast cancer. Ann Surg Oncol. 2015; 22:1408-1415.

32. Lopez M, Paul B, Hofmann A, Morizzi J, Wu QK, Charman SA, Innocenti A, Vullo D, Supuran CT, Poulsen S-A. $S$-Glycosyl primary sulfonamides - A new structural class for selective inhibition of cancer-associated carbonic anhydrases. J Med Chem. 2009; 52:6421-6432.

33. Lopez M, Trajkovic J, Bornaghi L, Innocenti A, Vullo D, Supuran C, Poulsen S. Design, Synthesis, and Biological Evaluation of Novel Carbohydrate-Based Sulfamates as Carbonic Anhydrase Inhibitors. J Med Chem 2011; 54:1481-1489.

34. Riganti C, Miraglia E, Viarisio D, Costamagna C, Pescarmona G, Ghigo D, Bosia A. Nitric oxide reverts the resistance to doxorubicin in human colon cancer cells by inhibiting the drug efflux. Cancer Res. 2005; 65:516-525.

35. Serra M, Scotlandi K, Manara MC, Maurici D, Lollini PL, De Giovanni C, Toffoli G, Baldini N. Establishment and characterization of multidrug-resistant human osteosarcoma cell lines. Anticancer Res. 1993; 13:323-329.

36. De Boo S, Kopecka J, Brusa D, Gazzano E, Matera L, Ghigo D, Bosia A, Riganti C. iNOS activity is necessary for the cytotoxic and immunogenic effects of doxorubicin in human colon cancer cells. Mol Cancer. 2009; 8:e108.

37. Doublier S, Riganti C, Voena C, Costamagna C, Aldieri E, Pescarmona G, Ghigo D, Bosia A. RhoA silencing reverts the resistance to doxorubicin in human colon cancer cells. Mol Cancer Res. 2008; 6:1607-1620.

38. Riganti C, Kopecka J, Panada E, Barak S, Rubinstein M. The Role of C/EBP- $\beta$ LIP in Multidrug Resistance. J Natl Cancer Inst. 2015; 107:djv046.

39. Riganti C, Voena C, Kopecka J, Corsetto P, Montorfano G, Enrico E, Costamagna C, Rizzo A, Ghigo D, Bosia A. Liposome-encapsulated doxorubicin reverses drugresistance by inhibiting P-glycoprotein in human cancer cells. Mol Pharm, 2011; 8:683-700. 